Supporting Information

\title{
Multifunctional Electromagnetic Interference \\ Shielding Ternary Alloy (Ni-W-P) Decorated Fabric with Wide-operating-range Joule Heating Performances
}

Yu Bai, ${ }^{\mathrm{a}, \mathrm{b}, \mathrm{c}}$ Feng Qin, ${ }^{*, \mathrm{a}, \mathrm{d}}$ Yinxiang Lu $u^{*, \mathrm{~b}}$

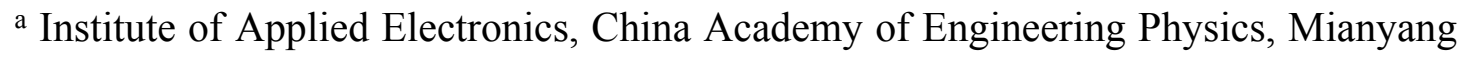
621900, China

b Department of Materials Science, Fudan University, Shanghai 200433, China

${ }^{c}$ Graduate School of China Academy of Engineering Physics, Beijing 100085, China

d Key Laboratory of Science and Technology on Complex Electromagnetic Environment, China Academy of Engineering Physics, Mianyang 621900, China

* Corresponding Authors

Email: fq_soul2000@163.com (Feng Qin); yxlu@fudan.edu.cn (Yinxiang Lu) 


\section{S1. Electroless nickel (Ni) plating laboratory process}

The as-cleaned polyamides (PA) fabric was then activated by seeding catalytic $\mathrm{Ni}^{0}$ nanoparticles (NPs) via an in-situ reduction method. A specific $\mathrm{Ni}^{0}$-activation was carried out as follows: (i) Typical surface modification of the fabric was first conducted through three reciprocating operations of APTMS immersion and air heating to fully graft the amine groups $\left(-\mathrm{NH}_{2}\right)$. The modified fabric sample was labeled as $\mathrm{PA}-\mathrm{NH}_{2}$; (ii) Thereafter, the obtained $\mathrm{PA}-\mathrm{NH}_{2}$ fabric was introduced into the $\mathrm{Ni}^{2+}$ aqueous solution at room temperature (RT) for 10 min to capture $\mathrm{Ni}^{2+}$ ions by bonding with $-\mathrm{NH}_{2}$ functional groups. The $\mathrm{Ni}^{2+}$ solution was preliminarily prepared by dissolving $\mathrm{NiSO}_{4} \cdot 6 \mathrm{H}_{2} \mathrm{O}(5 \mathrm{~g})$ and $\mathrm{C}_{2} \mathrm{H}_{10} \mathrm{BN}(0.3 \mathrm{~g})$ into $200 \mathrm{~mL} \mathrm{Na}{ }_{4} \mathrm{P}_{2} \mathrm{O}_{7}$ solution (25 g/L). The solution was then divided into two equal portions, one for the adsorption of $\mathrm{Ni}$ ions, and the other for electroless plating; (iii) $\mathrm{Ni}^{2+}$ ions on the fabric surface were finally in situ reduced by immersing the PA-Ni ${ }^{2+}$ fabric into $\mathrm{NaBH}_{4}$ solution $(0.7 \mathrm{M})$ at room temperature $(\mathrm{RT})$ for $10 \mathrm{~min}$.

Electroless $\mathrm{Ni}$ deposition procedure was carried out immediately after $\mathrm{Ni}^{0} \mathrm{NPs}$ activation by soaking $\mathrm{PA}^{-\mathrm{Ni}^{0}}$ fabric into a one-pot electroless bath prepared previously at RT for $60 \mathrm{~min}$. Upon withdrawing from one-pot plating bath, the fabric samples were rinsed with DI water and placed in oven at $40{ }^{\circ} \mathrm{C}$ for $15 \mathrm{~min}$ to facilitate surface drying. As a result, Ni coated PA fabric was successfully prepared. 


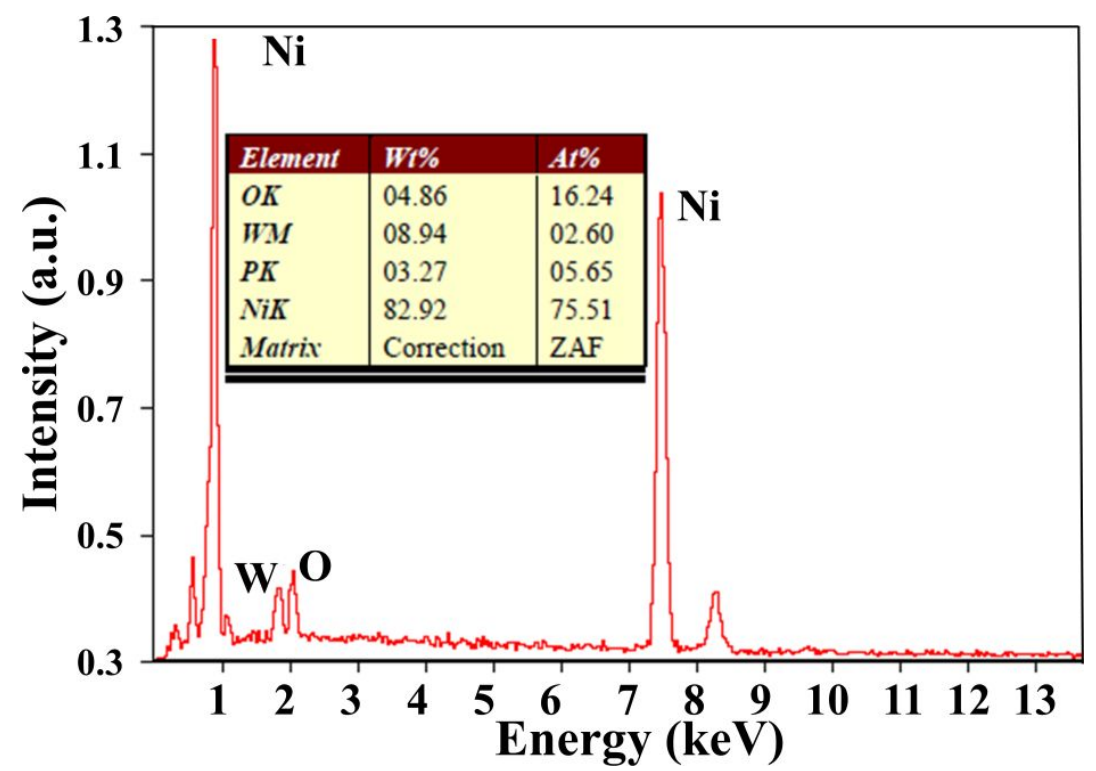

Figure S1. EDX analysis and element composition for Ni-W-P-N3 coated PA-5 fabric. 


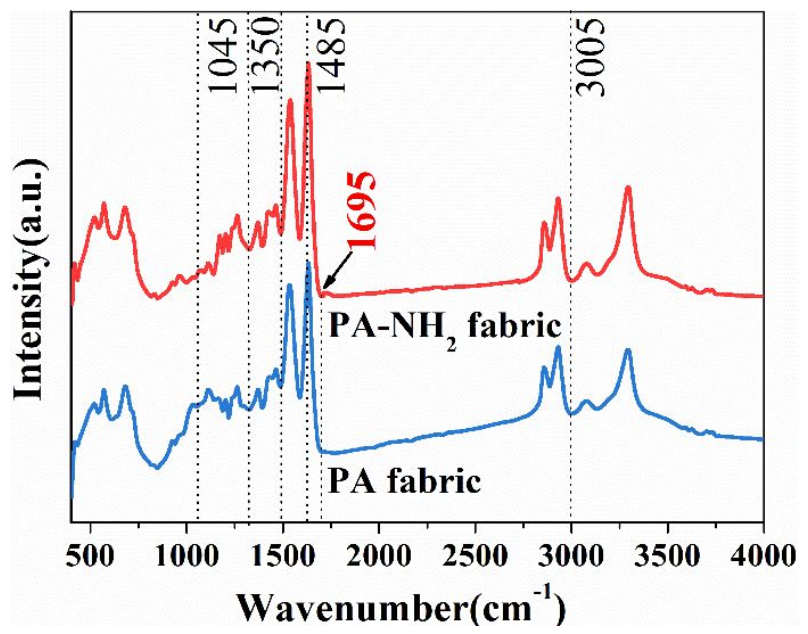

Figure S2. FTIR spectra of pristine PA fabric and $\mathrm{PA}-\mathrm{NH}_{2}$ fabric. 

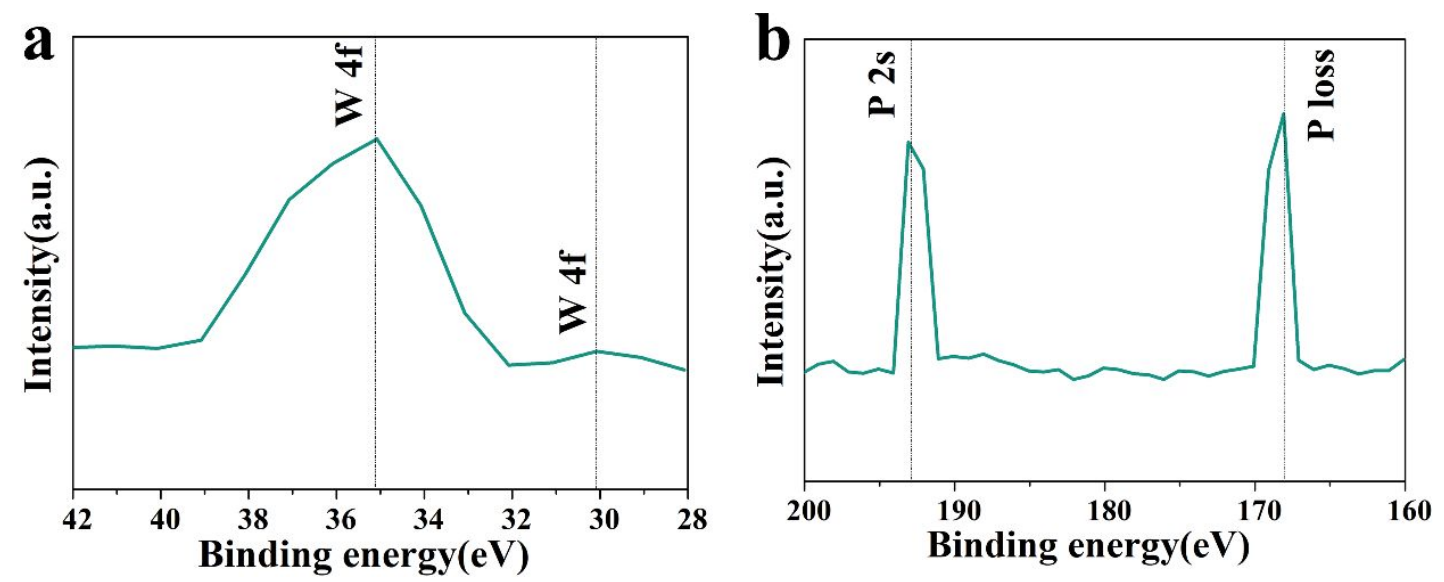

Figure S3. (a) XPS spectra of W 4f. (b) XPS spectra of P 2p and P loss. 


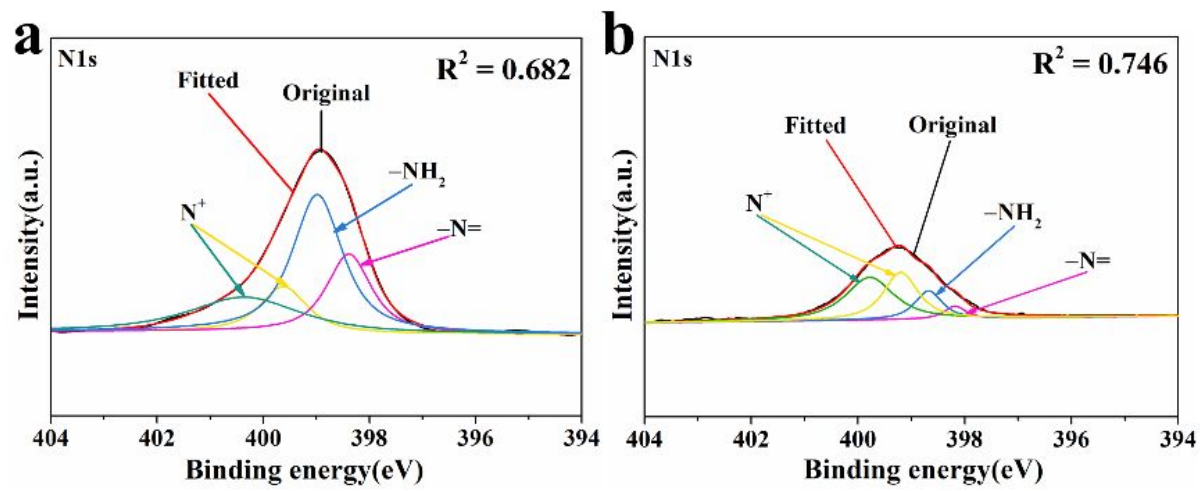

Figure S4. (a) N 1s spectra from PA-NH $\mathrm{N}_{2}$ fabric. (b) $\mathrm{N}$ 1s spectra from $\mathrm{Ni}-\mathrm{W}-\mathrm{P}-\mathrm{N} 3$ coated PA-5 fabric. 


\section{S2. Parameters employed in simulation of $\mathrm{Ni}-\mathrm{W}-\mathrm{P}$ coated $\mathrm{PA}$ fabric}

In the simulation model, surface plane of the fabric model is parallel to XY plane. Moreover, the incident wave is a uniform plane wave along the propagation vector $k$. These designs are aimed to make the model establishment and simulation more convenient.

The electrical conductivity $\sigma$ and magnetic permeability $\mu_{i}$ of simulated PA fabric were set as default $\left(\sigma=3.5 \mathrm{~S} / \mathrm{m}, \mu_{i}=1 \mathrm{H} / \mathrm{m}\right)$. In the meanwhile, the $\mathrm{Ni}-\mathrm{W}-\mathrm{P}$ alloy coating was considered as lossy metal material, which is determined by the input of $\sigma$ and $\mu_{i}$. The electrical conductivity of the alloy coating was measured before simulation, while the value of magnetic permeability $\mu_{i}$ can be calculated from the following equation:

$$
\mu_{i}=\frac{\left(M_{s}^{2}\right)}{a k H_{c} M_{s}+b \lambda \zeta}
$$

where $M_{S}$ is the saturation magnetization and $H_{c}$ is the coercivity, $\lambda$ is the magneto strictive constant, $\xi$ is elastic strain parameter of the crystal, and $k$ is a proportional coefficient, $\mathrm{a}$ and $\mathrm{b}$ are two constants which depend on the composition of the material itself. Among them, $M_{S}$ and $H_{c}$ can be obtained by VSM test. The remaining constants are determined by the international standards. ${ }^{\mathrm{S} 1} \mathrm{~A}$ typical hysteresis loop of VSM test result for Ni-W-P-N3 coated PA-3 fabric is shown in Figure S6. Notably, for the samples with determined Ni-W ratio and different mesh size, the $\sigma$ and $\mu_{i}$ were set as the measured value of Ni-W-P-N $x$ coated PA-5 fabric $(x=0,1,2,3,4,5)$, shown in Table S2. 


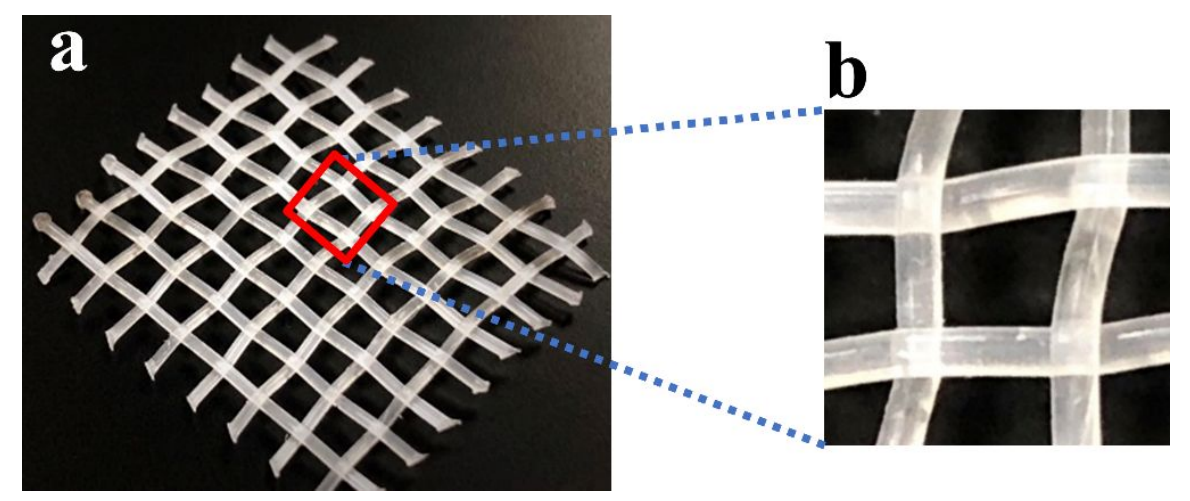

Figure S5. (a) Digital image of Ni-W-P-N3 coated PA-3 fabric. (b) Digital image of the unit for Ni-W-P-N3 coated PA-3 fabric. 


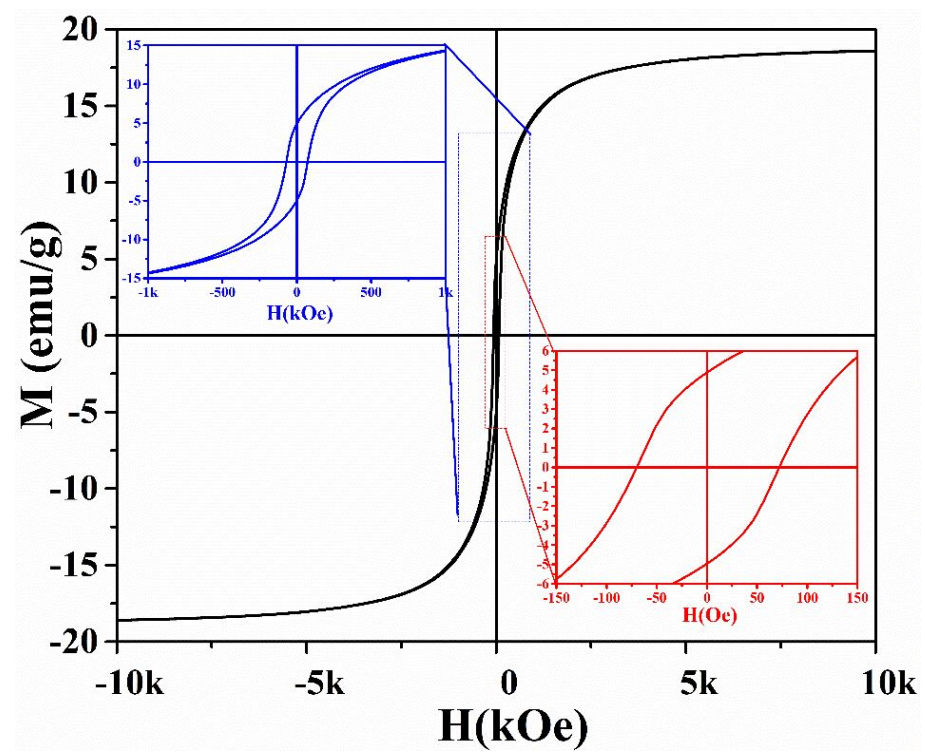

Figure S6. Magnetic hysteresis loop of the Ni-W-P-N3 coated PA-3 fabric sample with the magnetic field between -10 and $10 \mathrm{kOe}$. Insets: enlarged views of magnetic hysteresis loop in the region of -1 to $1 \mathrm{kOe}$ (top left) and -150 to $150 \mathrm{Oe}$ (bottom right), respectively. 


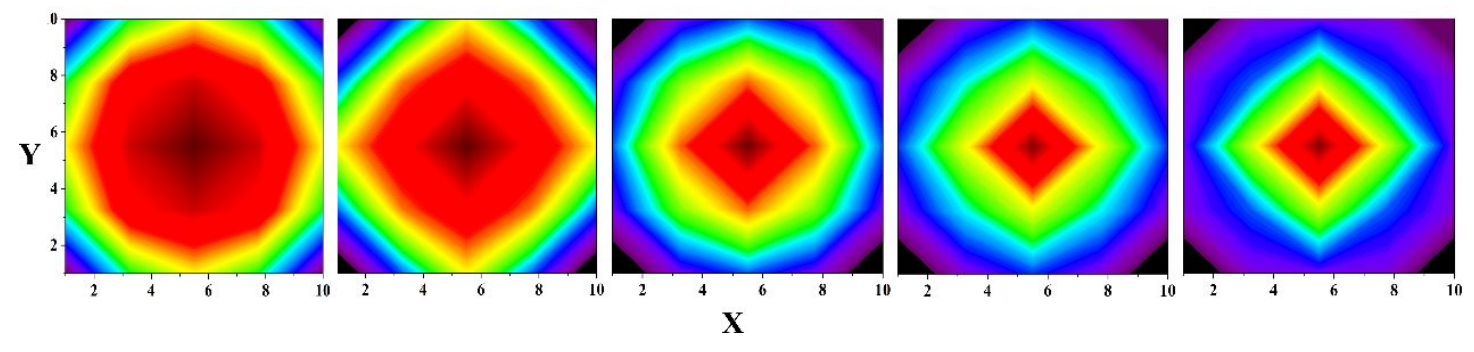

Figure S7. Two-dimensional electric field intensity distribution profiles. 


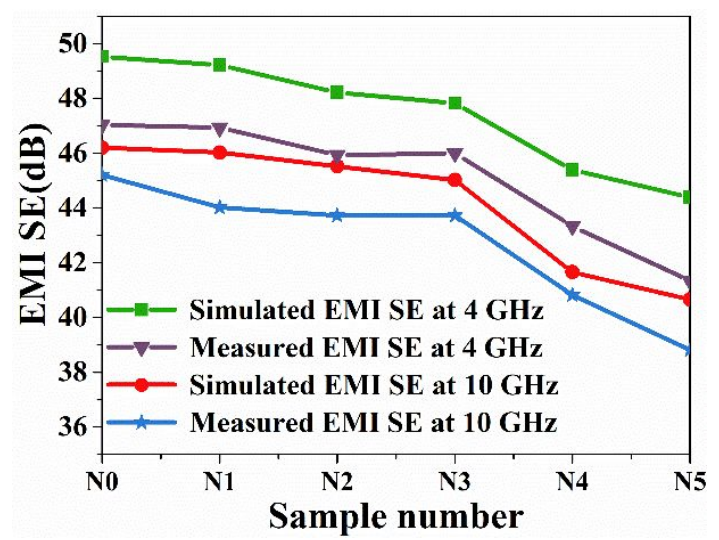

Figure S8. EMI SEs of Ni-W-P-N $x$ coated PA-5 fabric at frequency of $4 \mathrm{GHz}$ and $10 \mathrm{GHz}$. 


\section{S3. Experimental platform for high temperature resistance measurement}

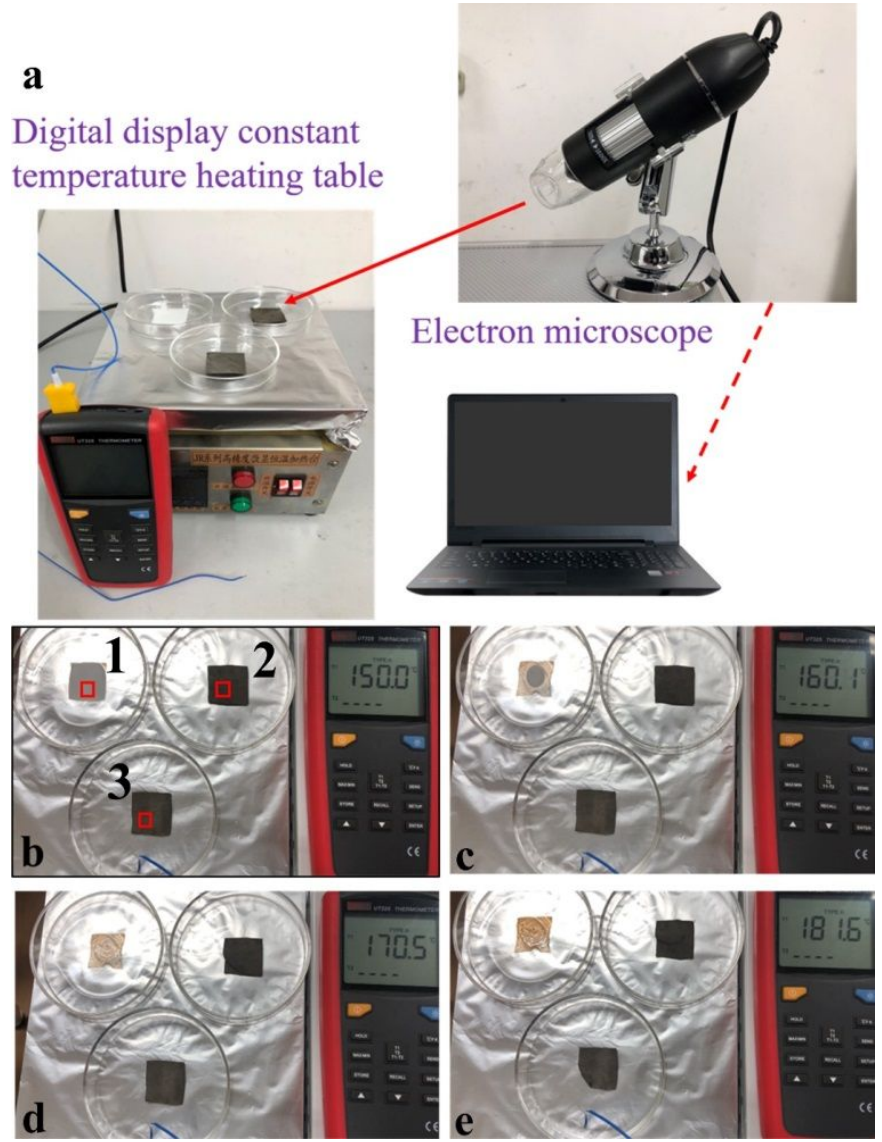

Figure S9. (a) Digital image of the real-time monitoring platform. (b-e) Digital diagrams of the pristine PA fabric, Ni coated PA fabric and Ni-W-P-N3 coated PA-5 fabric at the temperatures of (b) $150{ }^{\circ} \mathrm{C}$, (c) $160{ }^{\circ} \mathrm{C}$, (d) $170{ }^{\circ} \mathrm{C}$, and (e) $180{ }^{\circ} \mathrm{C}$, respectively.

The experimental heating platform adopts high-precision constant temperature heating stage with digital display (JR series). The electron microscope with a magnification of 50-5000 was used for microscopic observation of samples during heating. 


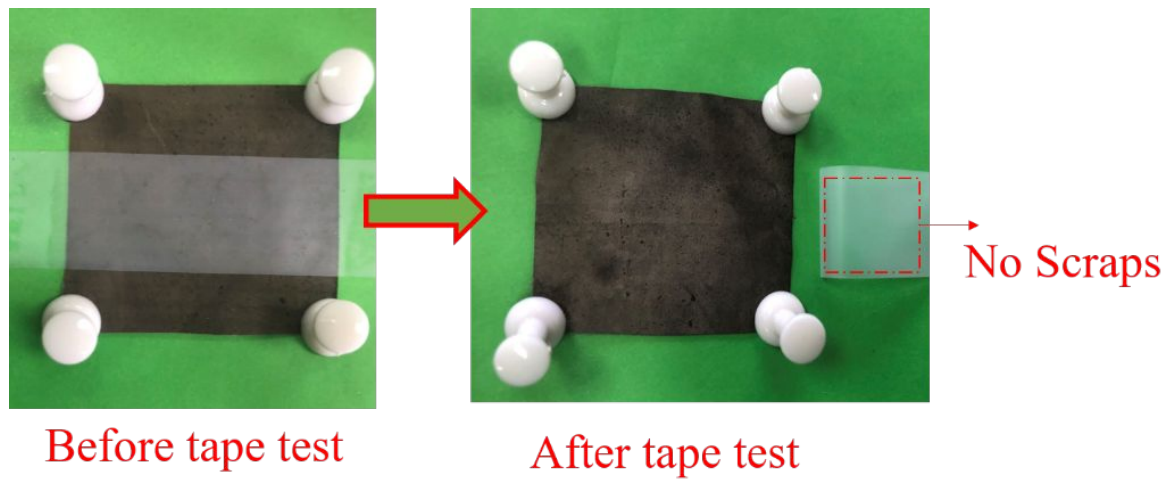

Figure S10. Schematic image of $\mathrm{Scotch}{ }^{\circledR}$ tape test for Ni-W-P-N3 coated PA-5 fabric. 
Table S1. XPS atomic ratio (\%) of fabric samples (Errors in determination $\pm 1 \%$ ).

\begin{tabular}{ccccc}
\hline$(\%)$ & $\mathrm{PA}$ & $\mathrm{PA}^{-\mathrm{NH}_{2}}$ & ${\mathrm{PA}-\mathrm{Ni}^{2+}}^{+}$ & $\mathrm{PA}-\mathrm{Ni}^{0}$ \\
$\mathrm{C} 1 \mathrm{~s}$ & 74.5 & 56.46 & 51.66 & 47.43 \\
$\mathrm{~N} 1 \mathrm{~s}$ & 10.07 & 18.06 & 3.7 & 1.86 \\
$\mathrm{O} 1 \mathrm{~s}$ & 13.76 & 12.26 & 8.13 & 44.78 \\
$\mathrm{Si} 2 \mathrm{p}$ & 1.67 & 13.22 & 35 & 5.01 \\
$\mathrm{Ni2p}$ & & & 1.51 & 0.92 \\
\hline
\end{tabular}


Table S2. Electrical conductivity $\sigma$, saturation magnetization $M_{s}$ and coercivity $H_{c}$ of Ni-W-P-N $x$ coated PA-5 fabric $(x=0,1,2,3,4,5)$.

\begin{tabular}{ccccccc}
\hline & $\mathrm{N} 0$ & $\mathrm{~N} 1$ & $\mathrm{~N} 2$ & $\mathrm{~N} 3$ & $\mathrm{~N} 4$ & $\mathrm{~N} 5$ \\
\hline$\sigma(\mathrm{S} / \mathrm{m})$ & $3.66 \times 10^{3}$ & $3.59 \times 10^{3}$ & $3.52 \times 10^{3}$ & $3.43 \times 10^{3}$ & $3.17 \times 10^{3}$ & $2.97 \times 10^{3}$ \\
$\boldsymbol{M}_{\boldsymbol{s}}(\mathrm{emu} / \mathrm{g})$ & 5.19 & 5.08 & 4.93 & 4.89 & 4.52 & 3.19 \\
$\boldsymbol{H}_{\boldsymbol{c}}(\mathrm{Oe})$ & 72.78 & 73.86 & 74.98 & 77.64 & 83.56 & 103.98 \\
\hline
\end{tabular}


Table S3. Corrosion current density $\left(I_{\text {corr }}\right)$ and Corrosion potential $\left(E_{\text {corr }}\right)$ of Ni-W-P ternary alloy coated flexible fabric (1) and single metal Ni coated fabric (2).

\begin{tabular}{|c|c|c|c|c|c|c|}
\hline & \multicolumn{3}{|c|}{$I_{\text {corr }}\left(\mathrm{A} \cdot \mathrm{cm}^{-2}\right)$} & \multicolumn{3}{|c|}{$E_{\text {corr }}(\mathrm{V})$} \\
\hline sample & 3.5 wt. $\% \mathrm{NaCl}$ & 10 wt. $\% \mathrm{HCl}$ & 10 wt. $\% \mathrm{NaOH}$ & 3.5 wt. $\% \mathrm{NaCl}$ & 10 wt. $\% \mathrm{HCl}$ & 10 wt. $\% \mathrm{NaOH}$ \\
\hline 1 & $7.879 \times 10^{-8}$ & $1.418 \times 10^{-6}$ & $-9.622 \mathrm{e} \times 10^{-4}$ & -0.620 & -0.056 & -0.694 \\
\hline 2 & $7.091 \times 10^{-6}$ & $6.366 \times 10^{-5}$ & $-9.972 \times 10^{-4}$ & -0.577 & 0.003 & -0.276 \\
\hline
\end{tabular}


Table S4. Comparison of anti-corrosion property of various fabrics.

\begin{tabular}{|c|c|c|c|c|c|}
\hline Substrate & Metallic coating & Electrolyte & $I_{\text {corr }}\left(\mathrm{A} \cdot \mathrm{cm}^{-2}\right)$ & $E_{\text {corr }}(\mathrm{V})$ & Refs. \\
\hline Carbon steel & $\mathrm{Cu}-\mathrm{P}$ & $3.5 \mathrm{wt} \% \mathrm{NaCl}$ & $6.53 \times 10^{-6}$ & -0.4726 & {$[\mathrm{~S} 2]$} \\
\hline PET film & $\mathrm{Cu}-\mathrm{Co}-\mathrm{P}$ & $3.5 \mathrm{wt} \% \mathrm{NaCl}$ & $4.516 \times 10^{-6}$ & -0.608 & [S3] \\
\hline PET film & $\mathrm{Ni}-\mathrm{P}$ & $3.5 \mathrm{wt} \% \mathrm{NaCl}$ & $1.07 \times 10^{-7}$ & -0.299 & {$[\mathrm{~S} 3]$} \\
\hline Polyester fabric & $\mathrm{Cu}-\mathrm{Ni}$ & $3.5 \mathrm{wt} \% \mathrm{NaCl}$ & $4.67 \times 10^{-6}$ & -0.511 & [S4] \\
\hline Polyester fabric & $\mathrm{Ni}-\mathrm{P} / \mathrm{Cu}-\mathrm{Ni}$ & $3.5 \mathrm{wt} \% \mathrm{NaCl}$ & $1.81 \times 10^{-7}$ & -0.313 & {$[\mathrm{~S} 4]$} \\
\hline Fabric-supported PANI & $\mathrm{Co}-\mathrm{Ni}$ & $3.5 \mathrm{wt} \% \mathrm{NaCl}$ & $1.272 \times 10^{-5}$ & -0.333 & {$[\mathrm{~S} 5]$} \\
\hline PA fabric & $\mathrm{Ni}$ & $3.5 \mathrm{wt} \% \mathrm{NaCl}$ & $-7.091 \times 10^{-6}$ & -0.577 & {$[\mathrm{~S} 5]$} \\
\hline PA fabric & $\mathrm{Ni}-\mathrm{W}-\mathrm{P}$ & $3.5 \mathrm{wt} \% \mathrm{NaCl}$ & $-7.879 \times 10^{-8}$ & -0.620 & This work \\
\hline
\end{tabular}




\section{REFERENCES}

(S1) Lv, R. T.; Cao, A. Y.; Kang, F. Y.; Wang, W. X.; Wei, J. Q.; Gu, J. L.; Wang, K.

L.; Wu, D. H. Single-crystalline Permalloy Nanowires in Carbon Nanotubes:

Enhanced Encapsulation and Magnetization. J. Phys. Chem. C 2007, 111, $11475-11479$.

(S2) Faraji, S.; Rahim, A. A.; Mohamed, N.; Sipaut, C. S.; Raja, B. Corrosion Resistance of Electroless $\mathrm{Cu}-\mathrm{P}$ and $\mathrm{Cu}-\mathrm{P}-\mathrm{SiC}$ Composite Coatings in $3.5 \% \mathrm{NaCl}$. Arabian J. Chem. 2013, 6, 379-388.

(S3) Hou, L.; Bi. S. Y.; Zhao, H.; Xu, Y. M.; Mu, Y. H.; Lu, Y. X. Electroless Plating Cu-Co-P Polyalloy on UV/ozonolysis Irradiated Polyethylene Terephthalate Film and Its Corrosion Resistance. Appl. Surf. Sci. 2017, 403, 248-259.

(S4) Jiang, S. X.; Guo, R. H. Electromagnetic Shielding and Corrosion Resistance of Electroless Ni-P/Cu-Ni Multilayer Plated Polyester Fabric. Surf. Coat. Technol. 2011, 205, 4274-4279.

(S5) Bi, S. Y.; Zhao, H.; Hou, L.; Lu, Y. X. Comparative Study of Electroless Co-Ni-P Plating on Tencel Fabric by $\mathrm{Co}^{0}$-based and $\mathrm{Ni}^{0}$-based Activation for Electromagnetic Interference Shielding. Appl. Surf. Sci. 2017, 419, 465-475. 